\title{
Improvement of Stability and Transdermal Delivery of Bioactive Compounds in Green Robusta Coffee Beans Extract Loaded Nanostructured Lipid Carriers
}

\author{
Nichcha Nitthikan (iD, ${ }^{1}$ Pimporn Leelapornpisid, ${ }^{2}$ Surapol Natakankitkul, ${ }^{2}$ \\ Wantida Chaiyana, ${ }^{2}$ Monika Mueller, ${ }^{3}$ Helmut Viernstein, ${ }^{3}$ and Kanokwan Kiattisin $\mathbb{D}^{2}$ \\ ${ }^{1}$ Department of Pharmaceutical Science, Faculty of Pharmacy, Chiang Mai University, Chiang Mai 50200, Thailand \\ ${ }^{2}$ Innovation Center for Holistic Health, Nutraceuticals, and Cosmeceuticals, Faculty of Pharmacy, Chiang Mai University, \\ Chiang Mai 50200, Thailand \\ ${ }^{3}$ Department of Pharmaceutical Technology and Biopharmaceutics, University of Vienna, Althanstrasse 14, Vienna 1090, Austria
}

Correspondence should be addressed to Kanokwan Kiattisin; ppp_pook@hotmail.com

Received 19 January 2018; Revised 29 March 2018; Accepted 3 April 2018; Published 10 May 2018

Academic Editor: Paresh Chandra Ray

Copyright (c) 2018 Nichcha Nitthikan et al. This is an open access article distributed under the Creative Commons Attribution License, which permits unrestricted use, distribution, and reproduction in any medium, provided the original work is properly cited.

\begin{abstract}
The aim of this study was to develop green robusta coffee beans extract loaded nanostructured lipid carriers (NLCs) for enhancing dermal application and its efficiency. The green robusta coffee beans extract cultivated in Chumphon (CP) exhibited the highest antioxidant activity in the 2,2-diphenyl-1-picrylhydrazyl (DPPH) radical scavenging assay with $\mathrm{IC}_{50}$ of $34.1 \pm 0.9 \mu \mathrm{g} / \mathrm{ml}$, lipid peroxidation inhibition with percentage inhibition of $38.8 \pm 1.7$, and ferric reducing antioxidant power (FRAP) assay with a FRAP value of $234.5 \pm 12.3 \mathrm{mM} \mathrm{FeSO}_{4} / \mathrm{g}$. The extract contained caffeine, chlorogenic acid, and caffeic acid as major compounds. The anti-inflammatory test indicated that CP could decrease the secretion of IL-6 in macrophage cells and caused no irritation to blood vessels on the irritation test by hen's egg test chorioallantoic membrane (HET-CAM) assay. The particle size of CP-loaded NLCs was $158.1 \pm 0.2 \mathrm{~nm}$ with a narrow polydispersity index and showed no noticeable difference after the stability test. Entrapment efficacy of CP-loaded NLCs was found to be over $60 \%$. Caffeine and chlorogenic acid in CP-loaded NLCs were released sustainably and penetrated deeper into the skin than the extract in a conventional emulsion. In conclusion, the CP-loaded NLCs can be further used in cosmetics for dermal applications due to good efficacy and safety.
\end{abstract}

\section{Introduction}

Coffee has been a major economic plant in Thailand for a long time. Thailand is the third largest producer of coffee in Asia. The most widely cultivated species is Coffea canephora or robusta, which accounts for $99 \%$ of coffee production in Thailand [1]. Conditions in the south of Thailand are perfect for growth, such as Chumphon, Nakhrn Si Thammarat, Yala, and Krabi provinces. Geography has a strong effect on the characteristics and physiological properties of coffee beans, such as flavors, quality, and chemical content [2]. Despite the lower quality of robusta coffee beans, it is popular as instant coffee in the beverage industry [3]. Green coffee beans contain polyphenol compounds, such as chlorogenic acid and its related compounds (caffeic acid, ferulic acid, and coumaric acid) which are used to inhibit the oxidative stress [4]. Phenolic compounds have attracted interest because of their antioxidant potential and anti-inflammatory activity $[5,6]$. According to a previous scientific study, green coffee beans contain a higher amount of chlorogenic acid than roasted coffee beans and other plants [7]. Our preliminary study found that the green robusta coffee beans extract contained phenolic compounds that were unstable under light and temperature. The antioxidant activities of the extract declined at high temperature after a period of storage. These problems affected the stability of phenolic compounds, and thus nanostructured lipid carriers (NLCs) were selected to reduce this problem. 
Nanotechnology involves the synthesis of nanoparticles with a particle size ranging from 20 to $200 \mathrm{~nm}$ having been applied in food, pharmaceutical, and cosmetic industries. Several lipid nanoparticles including liposomes, nanoemulsions, and solid lipid nanoparticles (SLNs) have been studied for decades. Liposomes can contain lipophilic drugs and hydrophilic drugs. However, they have many disadvantages including low drug loading, drug leakage, and fast release [8]. Nanoemulsions are optically transparent or slightly opaque emulsion with a small droplet size. Nanoemulsions are unstable due to Ostwald ripening, and controlled drug release is improbable due to their small particle size. SLNs are the first generation of lipid nanoparticles, and NLCs are modified from SLNs as the second generation of lipid nanoparticles. SLNs are composed of solid lipids whereas NLCs consist of liquid lipids and solid lipids. Therefore, NLCs show higher compound loading capacity than SLNs. In addition, the releasing profile can be controlled by delivering the active compound to the target organs and improving the stability of the active compound. NLCs are more feasible than the other lipid nanoparticles. Characteristics of NLCs formulation depend on formulation conditions, such as different lipids, surfactants, and methods of synthesis. Different types of lipids in NLCs formulation can be generated as imperfectly structured solid matrix. This type provides imperfect lipid matrix structure that presents the gap between triglyceride fatty acid chains and increases the ability of loading extracts [9]. The imperfect structure leads to many benefits such as the enhancement of the stability of compounds that are sensitive to light oxidation and hydrolysis reactions [10]. NLCs were also used to improve their stability of active compounds and used as a delivery system to control the release of active compounds. Therefore, NLCs can increase entrapment efficiency, drug loading, physical stability, and skin permeation, and they seem to be a valuable delivery system for loading the active compound in this study.

The purposes of this study were to develop green robusta coffee beans extract-loaded NLCs for the improvement of the stability and permeation of the active compounds through the skin barrier.

\section{Materials and Methods}

2.1. Plant Materials. Green robusta coffee beans (Coffea canephora) were obtained from different regions in Thailand, including Chumphon, Yala, and Chiang Rai. They were collected during May to June, 2016. All samples were deposited in the herbarium of the Faculty of Pharmacy, Chiang Mai University, Thailand.

2.2. Chemical Materials. Sorbitan oleate (Span ${ }^{\circledR} 80$ ), 2,2diphenyl-1-picrylhydrazyl (DPPH), caffeine, caffeic acid, and chlorogenic acid were purchased from Sigma-Aldrich Inc., USA. Linoleic acid and 2,4,6 tripyridyl-s-triazine (TPTZ) were purchased from Fluka Buchs, Switzerland. Dulbecco's Modified Eagle's medium (DMEM) and fetal bovine serum were obtained from Biochrom, Berlin, Germany. Thiazolyl blue tetrazolium bromide (MTT), dimethyl sulfoxide (DMSO), and lipopolysaccharide (LPS) were obtained from Sigma-Aldrich, Darmstadt, Germany. Penicillin/streptomycin, L-glutamine, and trypan blue were purchased from Invitrogen ${ }^{\mathrm{TM}}$, Grand Island, NY, USA. Sunflower oil and canola oil were purchased from Lam Soon CO., Ltd., Thailand. Acetic acid and acetonitrile were purchased from Labscan Ltd., Ireland. Cetyl alcohol, stearyl alcohol, Cremophor ${ }^{\circledR}$ A25, and Tween ${ }^{\circledR} 20$ were purchased from United Chemical \& Trading CO., Ltd., Thailand. Methanol was purchased from Labscan Asia Co., Ltd., Thailand. Acetate buffer and ferric chloride $\left(\mathrm{FeCl}_{3}\right)$ were purchased LOBA Chemie, India.

2.3. Extraction. The green robusta coffee beans were ground and dried in a hot air oven at $50 \pm 2^{\circ} \mathrm{C}$ for $24 \mathrm{~h}$. Those beans were ground with blender (600 W, Viva Collection Blender, Phillip) and reduced to the same size with a 120-mesh sieve shaker $(125 \mu \mathrm{m})$ (Thomas scientific, USA). The ground beans were macerated with $50 \%$ ethanol (v/v) in water for $48 \mathrm{~h}, 3$ cycles. After filtration through Whatman ${ }^{\circledR}$ filter paper number. 1, the solvent was evaporated by the rotary evaporator and dried to powder extracts by the spray dryer with outlet temperature of $70^{\circ} \mathrm{C}$ and inlet temperature of $120^{\circ} \mathrm{C}$. The obtained three different extracts including the green coffee beans extract cultivated in Chumphon (CP), green coffee beans extract cultivated in Yala (YL), and green coffee beans extract cultivated in Chiang Rai (CR). The extracts were stored in amber glass bottles at $2 \pm 2^{\circ} \mathrm{C}$ for further studies.

\subsection{Determination of the Antioxidant Activities}

2.4.1. DPPH Radical Scavenging Activity Assay. Scavenging activity of extracts on DPPH radicals was investigated by following the method of Iwai et al. [11] with some modifications. Briefly, an aliquot of $180 \mu \mathrm{l} \mathrm{DPPH}$ in ethanol was mixed with $20 \mu \mathrm{l}$ of each sample in 96-well plates and kept in the dark at room temperature for $30 \mathrm{~min}$. The absorbance of each sample was measured at $520 \mathrm{~nm}$ using a multimode detector, Beckman Coulter ${ }^{\circledR} \mathrm{GmbH}$, Austria. The results were calculated as $50 \%$ inhibitory concentration $\left(\mathrm{IC}_{50}\right)$. Chlorogenic acid, caffeine, and caffeic acid were used as reference standards.

2.4.2. Lipid Peroxidation Inhibitory Assay. The lipid peroxidation process based on the ferric-thiocyanate method was detected by following the method of Osawa and Namiki [12] with some modifications. An aliquot of $50 \mu \mathrm{l}$ of each extract $(20 \mathrm{mg} / \mathrm{ml})$ was mixed with $50 \mu \mathrm{l}$ of linoleic acid in $50 \%$ DMSO (v/v) in water, $50 \mu \mathrm{l}$ of $5 \mathrm{mM}$ ammonium thiocyanate $\left(\mathrm{NH}_{4} \mathrm{SCN}\right)$, and $50 \mu \mathrm{l}$ of $2 \mathrm{mM}$ ferrous chloride $\left(\mathrm{FeCl}_{2}\right)$. The mixture was placed in a hot air oven at $37 \pm$ $0.5^{\circ} \mathrm{C}$ for an hour, and then the reaction was investigated. The control was prepared as same as the sample without linoleic acid. Chlorogenic acid, caffeine, and caffeic acid were used as reference standards. The absorbance of each extract was detected at $490 \mathrm{~nm}$ using a multimode detector. The 
percentage inhibition was calculated by the following equation:

$$
\% \text { inhibition }=\left[\frac{(A c-A s)}{A c}\right] \times 100,
$$

where $A c$ is the absorbance of control, and $A s$ is the absorbance of the sample.

2.4.3. Ferric Reducing Antioxidant Power (FRAP) Assay. The ferric reducing antioxidant power of each extract was detected by following the method of Ou et al. [13] with some modifications. The FRAP reagent consisted of $0.3 \mathrm{M}$ acetate buffer of $\mathrm{pH} 3,10 \mathrm{mM}$ TPTZ dissolved in $40 \mathrm{mM}$ of $37 \% \mathrm{HCl}$ (v/v) in deionized water, and $20 \mathrm{mM}$ ferric chloride solution with a ratio of $10: 1: 1$. The concentration of each extract was $1 \mathrm{mg} / \mathrm{ml}$ dissolved in $20 \%(\mathrm{v} / \mathrm{v})$ Tween 20 in water, and $20 \mu \mathrm{l}$ of each sample was added into 96-well plates and reacted with $180 \mu \mathrm{l}$ of FRAP reagent. The mixture was incubated at room temperature for $5 \mathrm{~min}$. The dark blue solution was measured at $595 \mathrm{~nm}$ by a multimode detector. Ferrous sulfate $\left(\mathrm{FeSO}_{4}\right)$ was used as a standard with the equation

$$
y=0.1405 x+0.0287
$$

where $y$ is the absorbance at $595 \mathrm{~nm}$ and $x$ is concentration of $\mathrm{FeSO}_{4}\left(r^{2}=0.9926\right)$. The results of ferric reducing antioxidant power were reported as the FRAP value by the following equation:

$$
\text { FRAP value }\left(\frac{\mathrm{mM} \mathrm{FeSO}_{4}}{\mathrm{~g}}\right)=\frac{[(A-B)-0.0287]}{0.1405},
$$

where $A$ is absorbance of control of sample, and $B$ is absorbance of blank of sample.

\subsection{High Performance Liquid Chromatography (HPLC)} Analysis. HPLC analysis was performed by a C-18 column $\left(250 \times 4.6 \mathrm{~mm}\right.$ i.d., $5 \mu \mathrm{m}$, Mightysil $\left.{ }^{\circledR}\right)$ as a stationary phase. The mobile phase was isocratic elution that composed of $(A)$ acetonitrile and $(B) 1 \%$ glacial acetic acid $(15: 85, \mathrm{pH} 3)$ with the flow rate of $1.0 \mathrm{ml} / \mathrm{min}$ at room temperature $[14,15]$. Each extract was diluted in methanol with a concentration of $1 \mathrm{mg} / \mathrm{ml}$ and filtered through $0.45 \mu \mathrm{m}$ nylon syringe filters (Whatman Puradisc 25, USA). Ten microliters of extracts was injected into the HPLC column and was detected at $280 \mathrm{~nm}$ in triplicates. The reference standards were caffeine, chlorogenic acid, and caffeic acid. The assay method was validated before analyzing extracts (Table 1).

\subsection{Determination of the Anti-Inflammatory Activity}

2.6.1. Macrophage Cell Culture. The effect of the selected extract on the inflammatory process was examined by following the method of Mueller et al. [16]. The RAW 264.7 macrophage cells (American Type Culture Collection, ATCC-TIB-71) were seeded in 24-well plates with DMEM at a density of $2 \times 10^{6}$ cells per well and then incubated for $24 \mathrm{~h}$ at $37 \pm 0.5^{\circ} \mathrm{C}, 5 \% \mathrm{CO}_{2}$, and $90 \%$ humidity. The extract was added on the following day and incubated for $2 \mathrm{~h}$ with the
TABLE 1: Methods of validation requirement: linearity, limit of detection (LOD), limit of quantitation (LOQ), and \% RSD.

\begin{tabular}{lcccc}
\hline & Linearity & $\begin{array}{c}\text { Limit of } \\
\text { detection } \\
(\mu \mathrm{g} / \mathrm{mL})\end{array}$ & $\begin{array}{c}\text { Limit of } \\
\text { quantitation } \\
(\mu \mathrm{g} / \mathrm{mL})\end{array}$ & $\begin{array}{c}\% \\
\mathrm{RSD}\end{array}$ \\
\hline Caffeine & $r^{2}=0.994$ & 1.237 & 4.124 & 1.825 \\
Chlorogenic & $r^{2}=0.998$ & 0.488 & 1.627 & 1.627 \\
acid & & 0.630 & 2.101 & 1.998 \\
Caffeic acid & $r^{2}=0.979$ & & & \\
\hline
\end{tabular}

same condition. LPS was added at the final concentration of $1 \mu \mathrm{g} / \mathrm{ml}$ and continually incubated further for $24 \mathrm{~h}$. The supernatant was collected after centrifugation at $13,500 \mathrm{rpm}$ for $10 \mathrm{~min}$ before investigation of the IL- 6 secretion. The IL-6 concentration in supernatants $(100 \mu \mathrm{l})$ was determined by ELISA according to the manufacturer's protocol (R\&D Systems, Minneapolis, MN, USA). All incubation steps were performed at room temperature. The optical density at $450 \mathrm{~nm}$, corrected by the reference wavelength $570 \mathrm{~nm}$, was measured using a Genios Pro microplate reader (Tecan, Crailsheim, Germany). The negative control was untreated cells, and the positive control was cells incubated with ethanol and LPS.

2.6.2. Determination of the Cell Viability by MTT Assay. The MTT assay is the method to measure the reduction of 3-(4,5-dimethythiazol- 2-yl)-2,5-diphenyl tetrazolium bromide (MTT) to formazan by mitochondrial succinate dehydrogenase. The viability of LPS-stimulated cells was measured by the MTT assay. MTT solution $(5 \mathrm{mg} / \mathrm{ml})$ was added to the cells after removing the supernatant for ELISA. Cells were incubated for $2 \mathrm{~h}$ at $37 \pm 0.5^{\circ} \mathrm{C}, 5 \% \mathrm{CO}_{2}$, and $90 \%$ humidity. The supernatant was removed after incubation, and cells were lysed with lysis buffer (10\% SDS in $0.01 \mathrm{~N} \cdot \mathrm{HCl}$ ). The optical density was measured using a Genios Pro microplate reader at $570 \mathrm{~nm}$ and corrected by the reference at $690 \mathrm{~nm}$.2.6.3. Calculation of IL-6 Secretion for Anti-inflammatory Activity

The calculated concentrations of cytokines were normalized to MTT values to reduce any variation from differences in cell density by following this equation:

Normalized IL -6 secretion $=\left[\frac{\% \mathrm{IL}-6 \text { secretion }}{\% \text { cell viability }}\right] \times 100$.

The cells were treated with only LPS which was used as the positive control, and the amount of cytokine secretion was defined as $100 \%$. The results of the extracts were calculated as a percent of cytokine secretion.

2.7. Irritation Test by Hen's Egg Test Chorioallantoic Membrane (HET-CAM) Method. The extract showed the highest antioxidant activity, which was determined for the potential to generate acute irritation by modified HET-CAM method [17-19]. All fertilized eggs were received from Faculty of Agriculture, Chiang Mai University. Eggs were kept 7-9 days in an incubator at $37 \pm 1^{\circ} \mathrm{C}$ with $55 \pm 0.5 \%$ relative humidity. On day 10, each eggshell was carefully opened with a dentist 
rotary saw-blade, and white egg membrane was removed. The viable embryos with the yolk sac were returned to the incubator to protect them from cooling. The extract was prepared at a concentration of $0.5 \% \mathrm{w} / \mathrm{v}$ by dissolving in water. After that, $20 \mu \mathrm{l}$ of sample was dropped on the chorioallantoic membrane (CAM). The irritation reactions including vascular hemorrhages, vascular lysis, and vascular coagulation were observed using a stereo microscope within $5 \mathrm{~min}(300 \mathrm{sec})$ after adding the sample. Irritation score (IS) was calculated by the following equation:

$$
\text { IS }=\frac{(301-t(h))}{300 \times 5}+\frac{(301-t(l))}{300 \times 7}+\frac{(301-t(c))}{300 \times 9},
$$

where $t(h)$ is the time $(\mathrm{sec})$ when the sign of vascular hemorrhages first occurred, $t(l)$ is time (sec) when the sign of vascular lysis first occurred, and $t(c)$ is time (sec) when the sign of vascular coagulation first occurred. The results were classified as no irritation when IS was $0-0.9$, slight irritation when IS was 1.0-4.9, moderate irritation when IS was 5.0-8.9, and severe irritation when IS was 9.0-21.0. The blood vessel on CAM was continually investigated until $60 \mathrm{~min}$ for a long term irritation, and photographs were taken under the stereo microscope.

\subsection{Preparation of NLCs Formulations}

2.8.1. Development of NLCs. The major ingredients of NLCs are lipids, surfactants, and active compounds. Selected types of lipids affect the characteristics of NLCs formulation. The solubility of $\mathrm{CP}$ in lipids was determined by the test tube method [20]. The CP (1 mg) was weighed in the test tube. Each solid lipid or liquid lipid that is maintained at $5^{\circ} \mathrm{C}$ above their melting point was added in increments until $\mathrm{CP}$ was completely dissolved. The amount of lipids required to solubilize CP was determined. The high shear homogenization and ultrasonication technique is a modified method for preparing NLCs $[21,22]$. The required hydrophilic lipophilic balance (rHLB) value of lipids was calculated for estimating the amount of surfactants in formulation. If the formulation uses amount of surfactants equal to the rHLB, the formulation with good stability and small particle size is obtained [23]. Briefly, the lipid mixture consisted of solid lipids and liquid lipids with the ratio of $1: 6(\% \mathrm{w} / \mathrm{w})$ that melted until $75^{\circ} \mathrm{C}$. The Span 80 and Cremophor A25 which contained 5\% w/w in placebo-NLCs (A1 and A2) and 7.5\% $\mathrm{w} / \mathrm{w}$ in placebo-NLCs (B1 and B2) were used as surfactants. Pre-emulsion occurred after mixing the oil phase and water phase with the high-shear homogenizer (Yellow line DI 25 basic, IKA Werke GmbH \& Co. KG, Germany) at 8,000 rpm for $5 \mathrm{~min}$. Pre-emulsion was then generated to NLCs using the high-intensity ultrasonic processor (Vibra cell ${ }^{\mathrm{TM}}$, Sonics \& Materials, USA) with $400 \mathrm{~W}, 3 \mathrm{sec}$ for the pulse on and off, $40 \%$ amplitude, and $5 \mathrm{~min}$ for placebo-NLCs (A1 and B1) and $15 \mathrm{~min}$ for placebo-NLCs (A2 and B2). All placeboNLCs were gently stirred until being cooled down to room temperature. Compositions of NLCs are shown in Table 2.

In the next step, CP-loaded NLCs were prepared by adding the $\mathrm{CP}$ into the lipid phase before mixing other
TABLE 2: Compositions of NLCs formulations (values are given in $\% \mathrm{w} / \mathrm{w})$.

\begin{tabular}{|c|c|c|c|c|c|}
\hline \multirow[b]{2}{*}{$\begin{array}{l}\text { Compositions } \\
(\% \mathrm{w} / \mathrm{w})\end{array}$} & \multicolumn{5}{|c|}{ Formulation } \\
\hline & $\begin{array}{c}\text { Placebo- } \\
\text { NLCs } \\
\text { A1 }\end{array}$ & $\begin{array}{c}\text { Placebo- } \\
\text { NLCs } \\
\text { A2 }\end{array}$ & $\begin{array}{c}\text { Placebo- } \\
\text { NLCs } \\
\text { B1 }\end{array}$ & $\begin{array}{c}\text { Placebo- } \\
\text { NLCs } \\
\text { B2 }\end{array}$ & $\begin{array}{c}\text { CP- } \\
\text { loaded } \\
\text { NLCs }\end{array}$ \\
\hline Cetyl alcohol & 0.5 & 0.5 & 0.5 & 0.5 & 0.5 \\
\hline Stearyl alcohol & 0.5 & 0.5 & 0.5 & 0.5 & 0.5 \\
\hline Sunflower oil & 3.0 & 3.0 & 3.0 & 3.0 & 3.0 \\
\hline Canola oil & 3.0 & 3.0 & 3.0 & 3.0 & 3.0 \\
\hline Span 80 & 2.81 & 2.81 & 3.27 & 3.27 & 3.27 \\
\hline $\begin{array}{l}\text { Cremophor } \\
\text { A25 }\end{array}$ & 2.19 & 2.19 & 4.25 & 4.25 & 4.25 \\
\hline $\mathrm{CP}$ & - & - & - & - & 0.5 \\
\hline $\begin{array}{l}\text { Sonication } \\
\text { time (min) }\end{array}$ & 5 & 15 & 5 & 15 & 15 \\
\hline
\end{tabular}

components. The final concentration of the CP-loaded NLCs was $0.5 \% \mathrm{w} / \mathrm{w}$.

2.8.2. Characterization of Prepared NLCs. Particle size, polydispersity index (PDI), and zeta potential of placeboNLCs and CP-loaded NLCs were detected by photon correlation spectroscopy (Zetasizer ${ }^{\circledR} \mathrm{ZS}$, Malvern Instruments Ltd., UK). Each formulation was diluted with deionized water at a ratio of $1: 100$. All measurements were done in triplicate at $25 \pm 0.5^{\circ} \mathrm{C}$.

2.8.3. Stability Study of NLCs Formulations. Placebo-NLCs and CP-loaded NLCs were kept in amber glass bottles and stored under various conditions using 6 cycles of heatingcooling (HC) method (changing between $4 \pm 0.5^{\circ} \mathrm{C}$ for $48 \mathrm{~h}$ and $45 \pm 0.5^{\circ} \mathrm{C}$ for $48 \mathrm{~h}$ ), room temperature (RT or $30 \pm$ $\left.0.5^{\circ} \mathrm{C}\right), 4 \pm 0.5^{\circ} \mathrm{C}$ and $45 \pm 0.5^{\circ} \mathrm{C}$ for 3 months. The characterization of NLCs formulations, the physical properties, and antioxidant activity were evaluated after storage.

2.9. Entrapment Efficiency and Extract Loading of CP-Loaded NLCs. Entrapment efficiency and extract loading were evaluated by the ultrafiltration method with some modifications [20]. In brief, CP-loaded NLCs were divided into 2 parts for analyzing entrapment efficacy: formulation for determining total $\mathrm{CP}$ and formulation for determining unloaded CP. $0.3 \mathrm{~g}$ of CP-loaded NLCs was dissolved in hexane and ethanol with a ratio of $6: 4$ and analyzed as total CP $\left[W_{\text {total }}\right]$ in formulation by HPLC. Hexane and ethanol helped to dissolve NLCs formulation for analyzing total CP in formulation including unloaded $\mathrm{CP}$ and loaded $\mathrm{CP}$ in NLCs. Other part of CP-loaded NLCs $(0.3 \mathrm{~g})$ was weighted and added into the top of the ultra centrifuge filter (Amicon ${ }^{\circledR}$ Ultra-1.5 ml, NMWCO $10 \mathrm{kDa}$, Merck, Germany). The ultra centrifuge filter was then centrifuged at $7,000 \mathrm{rpm}$ at $25^{\circ} \mathrm{C}$ for an hour. CP-loaded NLCs remained in the ultra centrifuge filter whereas the unloaded $\mathrm{CP}$ was dropped at the bottom of tube. The unloaded CP $\left[W_{\text {free }}\right]$ was diluted with methanol and analyzed by HPLC. An amount of the active compound in the solution was determined by HPLC. Finally, the 
percentage of entrapment efficiency (EE) and extract loading (EL) were calculated by the following equation.

$$
\begin{aligned}
& \% \mathrm{EE}=\frac{\left[W_{\text {total }}\right]-\left[W_{\text {free }}\right]}{\left[W_{\text {total }}\right]} \times 100, \\
& \% \mathrm{EL}=\frac{\left[W_{\text {total }}\right]-\left[W_{\text {free }}\right]}{\left[W_{\text {total }}\right]+\left[W_{\text {lipid }}\right]-\left[W_{\text {free }}\right]} \times 100,
\end{aligned}
$$

where $\left[W_{\text {total }}\right],\left[W_{\text {free }}\right]$, and $\left[W_{\text {lipid }}\right]$ are the amount of total CP, the amount of unloaded CP, and the amount of lipids used to prepare the formulation, respectively.

2.10. Skin Permeation Study. CP-loaded NLCs and CP in conventional emulsion were evaluated for skin permeation by Franz diffusion cells. The porcine skin was shaved and subcutaneous fat was removed. After that, it was placed on top of the receiver chamber and the epidermis turned to the donor compartment whereas dermis was closed to the receiver chamber. Phosphate buffer ( $\mathrm{pH}$ 5.5) was contained in the receiver chamber as receiver medium. The volume of receiver medium was $13 \mathrm{ml}$ and the temperature was set at $32 \pm 2^{\circ} \mathrm{C}$ and continuously stirred with a magnetic bar. $1 \mathrm{~g}$ of each formulation was added to the donor compartment. Receiver medium was withdrawn at $1,2,4,6,8$, and $10 \mathrm{~h}$. The porcine skin was turned into small pieces, immersed in methanol, and sonicated for $15 \mathrm{~min}$. The concentration of chlorogenic acid and caffeine in viable epidermis and dermis (VED) was detected by HPLC. For the determination of chlorogenic acid and caffeine in the stratum corneum (SC), the skin was stripped with 20 pieces of an adhesive tape using a $3 \mathrm{M}$ scotch magic ${ }^{\mathrm{TM}}$ tape. Each tape was charged with a weight of $300 \mathrm{~g}$ for $10 \mathrm{sec}$. The first tape strip was discarded. The 2nd to 20th tape strips were extracted with methanol to quantify the amount of chlorogenic acid and caffeine in the stratum corneum. The percentage accumulative of chlorogenic acid and caffeine in SC, VED, and solution after $10 \mathrm{~h}$ was calculated by the following equation.

$$
\% \text { accumulative }=\left(\frac{A_{\mathrm{sc}}, A_{\mathrm{ved}} \text { and } A_{\mathrm{so}}}{A_{\text {total }}}\right) \times 100 \%,
$$

where $A_{\mathrm{sc}}, A_{\mathrm{ved}}$, and $A_{\mathrm{so}}$ are an amount of chlorogenic acid and caffeine in stratum corneum, viable epidermis and dermis, and solution, respectively. $A_{\text {total }}$ is total amount of chlorogenic acid and caffeine in $1 \mathrm{~g}$ of formulation.

2.11. Statistical Analysis. All experiments in this study were done in triplicates. The results were presented as the mean \pm standard deviation (SD). Statistical analysis used the SPSS statistic version 17.0 program.

Statistical significance was evaluated by one-way ANOVA at the probability level of 0.05 .

\section{Results and Discussion}

3.1. Green Robusta Coffee Beans Extracts. The percentage yields of green robusta coffee beans extracts and their
TABle 3: Percentage of yields and physical characteristic of green robusta coffee beans.

\begin{tabular}{lcc}
\hline Extracts & Yield (\%) & Physical characteristic \\
\hline CP & $9.6 \pm 0.7$ & Dry light green powder \\
YL & $7.7 \pm 0.2$ & Dry light green powder \\
CR & $8.1 \pm 0.7$ & Dry light green powder \\
\hline
\end{tabular}

TABLE 4: Antioxidant activities of green robusta coffee bean extracts detected by DPPH assay, lipid peroxidation inhibitory assay, and FRAP assay.

\begin{tabular}{lccc}
\hline Samples & $\begin{array}{c}\text { DPPH assay } \\
\mathrm{IC}_{50}(\mu \mathrm{g} / \mathrm{ml})\end{array}$ & $\begin{array}{c}\text { Lipid peroxidation } \\
\text { inhibitory assay } \\
\% \text { inhibition }\end{array}$ & $\begin{array}{c}\text { FRAP assay } \\
\text { FRAP value } \\
\left(\mathrm{mM} \mathrm{FeSO}_{4} / \mathrm{g}\right)\end{array}$ \\
\hline $\mathrm{CP}$ & $34.1 \pm 0.9^{\mathrm{a}}$ & $38.8 \pm 1.7^{\mathrm{a}}$ & $234.5 \pm 12.3^{\mathrm{a}}$ \\
$\mathrm{YL}$ & $44.2 \pm 1.4^{\mathrm{a}}$ & $14.4 \pm 0.4^{\mathrm{b}}$ & $231.8 \pm 3.1^{\mathrm{a}}$ \\
$\mathrm{CR}$ & $48.6 \pm 3.4^{\mathrm{a}}$ & $15.3 \pm 0.7^{\mathrm{b}}$ & $211.7 \pm 16.9^{\mathrm{a}}$ \\
$\mathrm{CA}$ & $7.1 \pm 1.2^{\mathrm{b}}$ & $45.3 \pm 0.4^{\mathrm{a}}$ & $234.5 \pm 0.1^{\mathrm{a}}$ \\
$\mathrm{CGA}$ & $10.5 \pm 1.3^{\mathrm{b}}$ & $34.1 \pm 1.8^{\mathrm{a}}$ & $234.5 \pm 0.1^{\mathrm{a}}$ \\
$\mathrm{CF}$ & $\mathrm{ND}$ & $\mathrm{ND}$ & $37.02 \pm 10.7^{\mathrm{b}}$ \\
\hline
\end{tabular}

Different letters within the same column mean significant difference $(p<0.05)$. ND: not detected, CP: green robusta coffee beans extract from Chumphon, YL: green robusta coffee beans extract from Yala, CR: green robusta coffee beans extract from Chaing Rai, CA: caffeic acid, CGA: chlorogenic acid, and CF: caffeine.

physical characteristics are presented in Table 3. All extracts were light green powders. The $\mathrm{CP}$ showed the highest percentage of yield as $9.6 \pm 0.7$ while the YL showed the lowest percentage of yield among all extracts. However, the results were not significantly different among all extracts grown in various locations.

3.2. Determination of Antioxidant Activity. Antioxidant activities of each extract by DPPH, lipid peroxidation inhibitory, and FRAP assays are shown in Table 4. Several assays for antioxidant activity were used to analyze various mechanisms of the antioxidants against free radicals. The $\mathrm{CP}$ demonstrated the best antioxidant activity among three extracts and caffeine in all assays. It showed the highest free radical scavenging activity of all extracts by the DPPH assay. The DPPH assay is based on the scavenging capacity of antioxidants by hydrogen donation and used to evaluate hydrophilic antioxidants, including chlorogenic acid and caffeic acid. These are phenolic compounds which are mostly found in green coffee beans [22]. Therefore, the scavenging capacity of extracts correlated with phenolic compounds in extracts. Those compounds consist of many hydroxyl groups that could scavenge reactive oxygen species (ROS) by donating hydrogen atoms [24]. The CP also showed better activity than chlorogenic acid which was detected by lipid peroxidation inhibitory assay. It can be assumed that $\mathrm{CP}$ could inhibit the oxidation reaction of unsaturated fatty acids by donating hydrogen atoms to stop the chain reaction. In addition, it possessed equal activity with chlorogenic acid and caffeic acid as shown by FRAP assay. The FRAP assay is based on the reduction of ferric iron $\left(\mathrm{Fe}^{3+}\right)$ complex to ferrous ion $\left(\mathrm{Fe}^{2+}\right)$ by electron donation of the antioxidant 


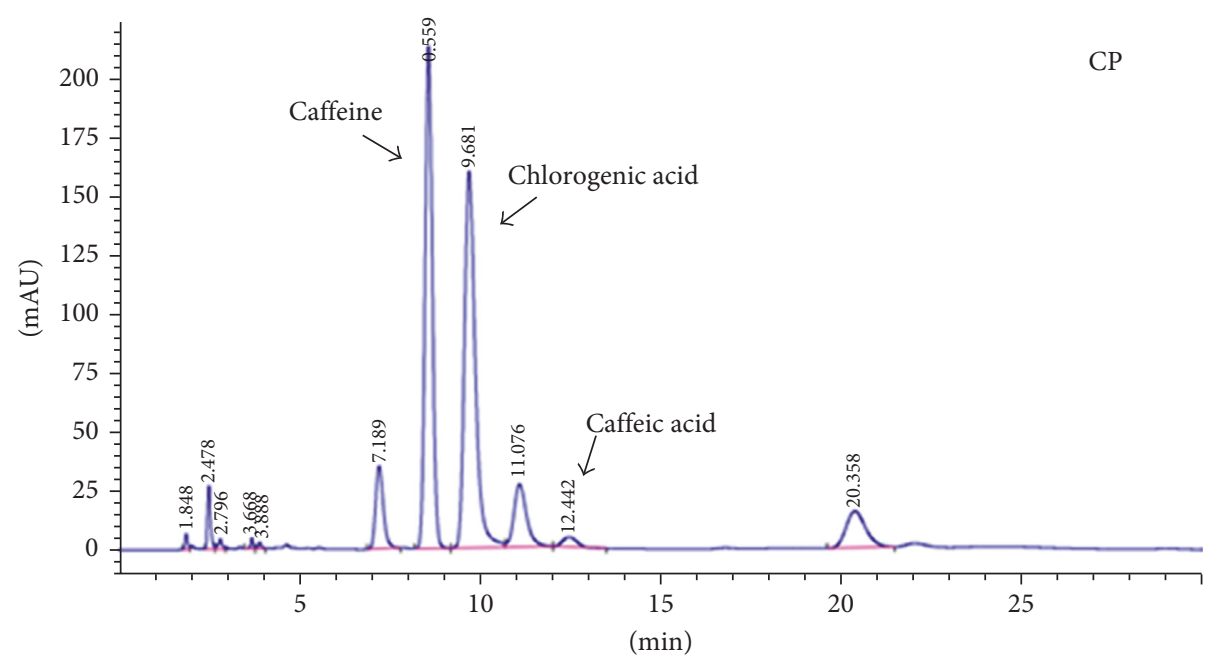

(a)

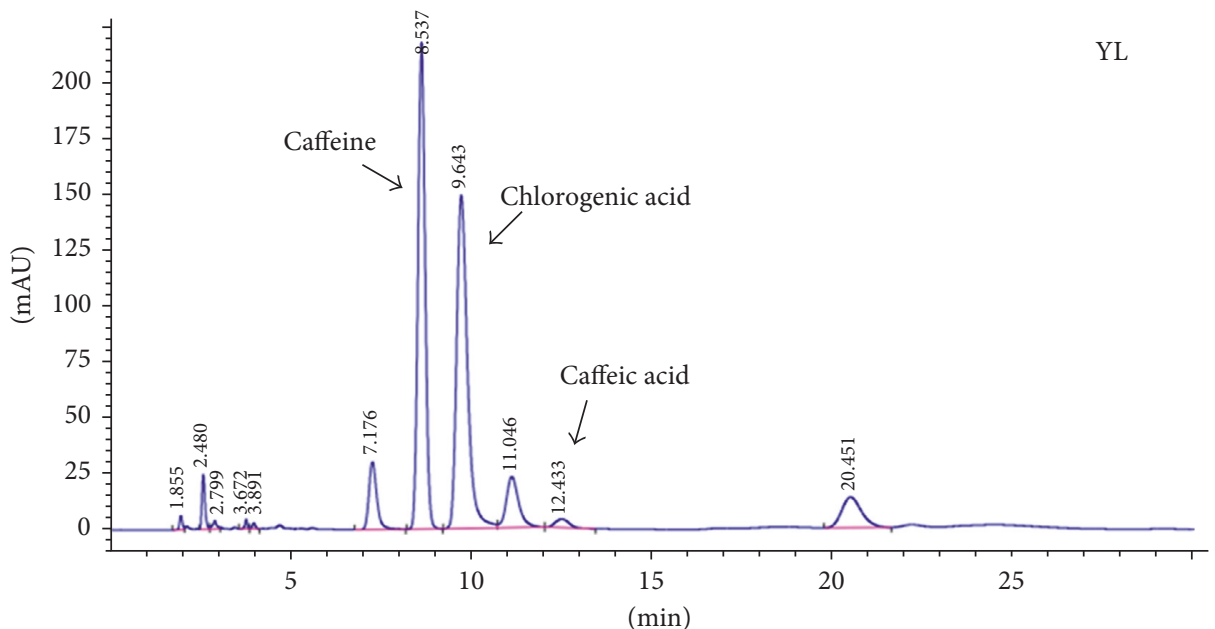

(b)

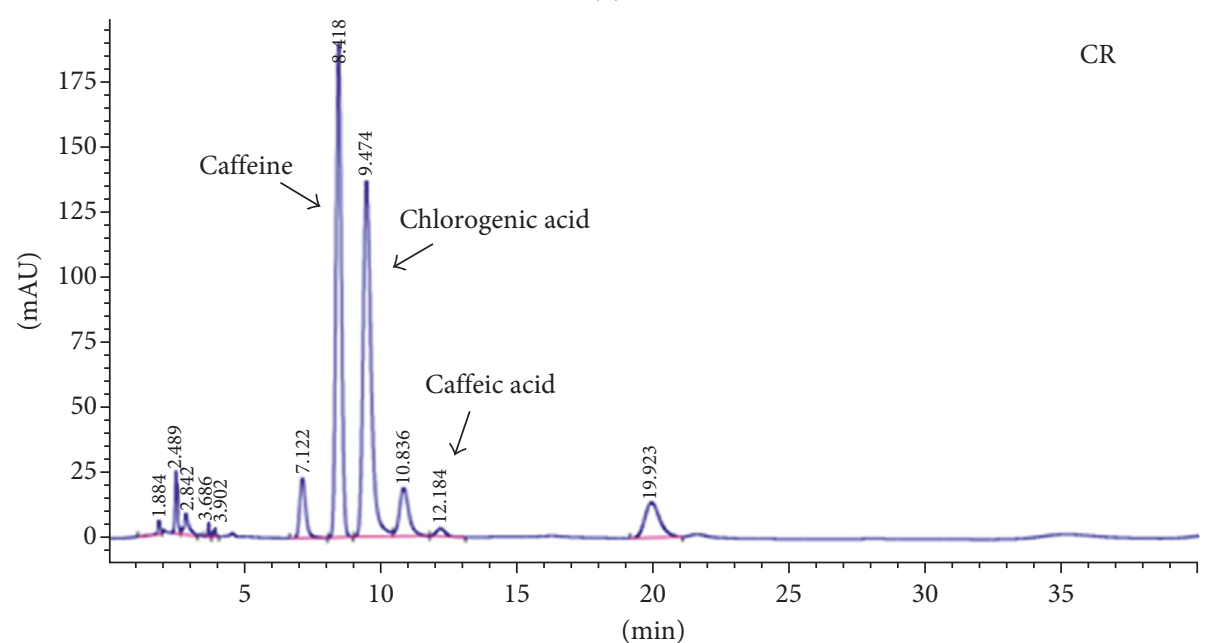

(c)

Figure 1: HPLC chromatograms of extracts: (a) CP, (b) YL, and (c) CR using HPLC at a wavelength $280 \mathrm{~nm}$.

agent $[25,26]$. Due to the high FRAP values of all extracts, it could be assumed that they had the ability to reduce $\mathrm{Fe}^{3+}$ to $\mathrm{Fe}^{2+}$ as well as act as a chelating agent.
3.3. High Performance Liquid Chromatography (HPLC) Analysis. Caffeine, chlorogenic acid, and caffeic acid could be clearly identified by HPLC with retention times of 8.049, 
9.491, and $12.051 \mathrm{~min}$, respectively. All extracts showed the major peak at the same standard retention time (Figure 1). It could be noticed that the major compounds in green robusta coffee beans were found in all extracts. However, different contents of caffeine and phenolic compounds in green coffee beans depended on temperature, weather, and location of plant growth [27]. Generally, robusta coffee is grown in the southern part of Thailand at elevations of 800 to $1,200 \mathrm{~m}$ above the sea level in an open area with full sunlight. It could be assumed that the $\mathrm{CP}$ was grown in a suitable location. Therefore, the level of chlorogenic acid content was higher than other extracts. Plants from different locations consisted of the same natural compounds, but the amounts of the compounds were different.

3.4. Anti-Inflammatory Activity. Interleukin 6 (IL-6) acts as a proinflammatory cytokine and is secreted by $\mathrm{T}$ cells and macrophages to stimulate the immune response. In this study, the effect of $\mathrm{CP}$ on the expression of inflammatory cytokines was evaluated. Anti-inflammatory activity was determined by studying the inhibition of the secretion of IL-6 on RAW 264.7 macrophages cells. The results are shown in Figure 2. All concentrations of CP were not toxic to the cells. Concentrations of CP between 0.05 and $0.1 \mathrm{mg} / \mathrm{ml}$ could decrease the IL- 6 secretion. The IL- 6 secretion in the presence of a high concentration of CP was not significantly different when compared to caffeine and the untreated control without LPS induction. It indicated that the extract had the ability to inhibit inflammatory activity due to a high amount of the caffeine content in the extract. Caffeine has been well known as a strong anti-inflammatory agent [28].

\subsection{Hen's Egg Test Chorioallantoic Membrane (HET-CAM)} Assay. The results of the irritation test using the HET-CAM assay are shown in Table 5. For the positive control, $1 \% \mathrm{w} / \mathrm{v}$ SLS in deionized water was used to induce an irritation effect on the chorioallantoic membrane (CAM). SLS is usually found in cosmetic products and causes acute skin irritation. SLS showed moderate irritation and vascular lysis. Solution of CP $0.5 \% \mathrm{w} / \mathrm{v}$ in deionized water presented the same result as $\mathrm{NaCl} 0.9 \% \mathrm{w} / \mathrm{v}$ in deionized water which was used as the negative control. The CP did not affect blood vessels and capillaries after $60 \mathrm{~min}$ of observation. The surfaces of the CAM and blood vessels are presented in Figure 3. It can be concluded that the $\mathrm{CP}$ was safe for usage in cosmetic products as an active ingredient since it showed no irritation. The HETCAM assay is a model for predicting the irritation effect on the conjunctiva. However, it has been used to assume the irritation of many types of cosmetic formulations [29, 30].

\subsection{Preparation of Placebo-NLCs and CP-Loaded NLCs}

3.6.1. Development of Placebo-NLCs. The solubility of CP in lipids is shown in Figure 4. The CP could dissolve in liquid lipids following this order: canola oil $>$ sunflower oil $>$ rice bran oil $>$ camellia oleifera seed oil. Solubility of CP in solid lipids followed this order: cety alcohol $>$ stearyl alcohol $>$ glyceryl

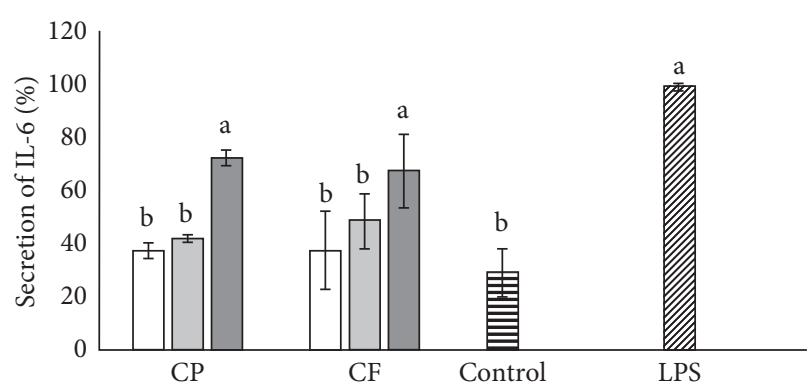

FIGURE 2: The influence of various concentrations of CP $(\square 0.10 \mathrm{mg} / \mathrm{ml}$, $\square 0.05 \mathrm{mg} / \mathrm{ml}$, and $\square 0.01 \mathrm{mg} / \mathrm{ml})$, caffeine (CF) $(\square 0.10 \mathrm{mg} / \mathrm{ml}$, $\square$ $0.05 \mathrm{mg} / \mathrm{ml}$, and $\square 0.01 \mathrm{mg} / \mathrm{ml}$ ), and RAW 264.7 cells without LPS (control) and cells induced with LPS (LPS) Different letters mean significant differences $(p<0.05)$.

TABLE 5: Irritation score and irritation assessment from HET-CAM assay.

\begin{tabular}{lcc}
\hline Samples & $\begin{array}{c}\text { Irritation } \\
\text { score }\end{array}$ & $\begin{array}{c}\text { Irritation } \\
\text { assessment }\end{array}$ \\
\hline CP $(0.5 \%$ in aqueous solution $)$ & 0.0 & No irritation \\
Negative control $(0.9 \% \mathrm{NaCl})$ & 0.0 & No irritation \\
Positive control $(1 \%$ SLS $)$ & $6.4 \pm 1.3$ & Moderate irritation \\
\hline
\end{tabular}

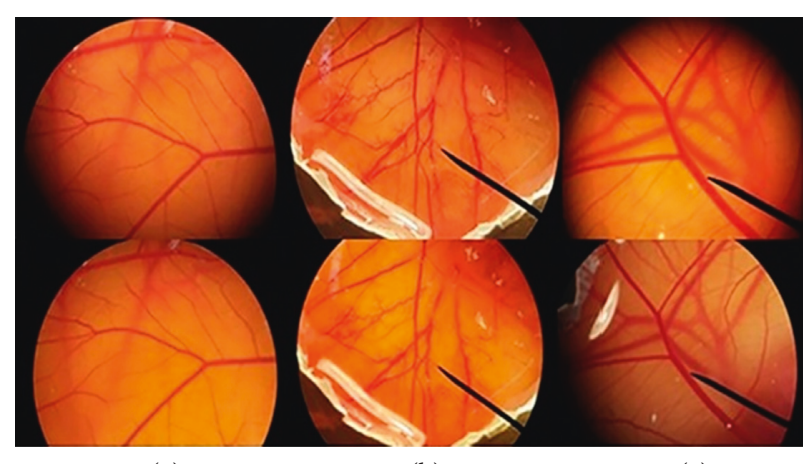

(a)

(b)

(c)

FIgURE 3: Photographs of CAM after 5 min (upper) and after $60 \mathrm{~min}$ (lower) exposure to (a) negative control $(0.9 \% \mathrm{NaCl}),(\mathrm{b})$ positive control (1\% SLS), and (c) CP in aqueous solution $(0.5 \%)$.

monostearate $>$ beeswax $>$ carnauba wax. From the solubility results mentioned above, canola oil, sunflower oil, cetyl alcohol, and stearyl alcohol were selected as the oil phase for NLCs preparation. Furthermore, the solubility of $\mathrm{CP}$ was evaluated in different lipid blends. The solubility of blended canola oil and sunflower oil and cetyl alcohol blended with stearyl alcohol were 1.37 and $0.78 \mathrm{mg} / \mathrm{ml}$, respectively. Therefore, canola oil (HLB 7) and sunflower oil (HLB 15) were used as liquid lipids and cetyl alcohol (HLB 15.5) and stearyl alcohol (HLB 15.5) were used as solid lipids in formulation. Span 80 (HLB 4.3) and Cremophor A25 (HLB 17) were selected for using as surfactants in NLC formulation. The required hydrophiliclipophilic balance value of lipids in formulation was 11-12, which is appropriate to produce stable NLCs.

The characteristics of placebo-NLCs are presented in Table 6 including the particle size, polydispersity index 


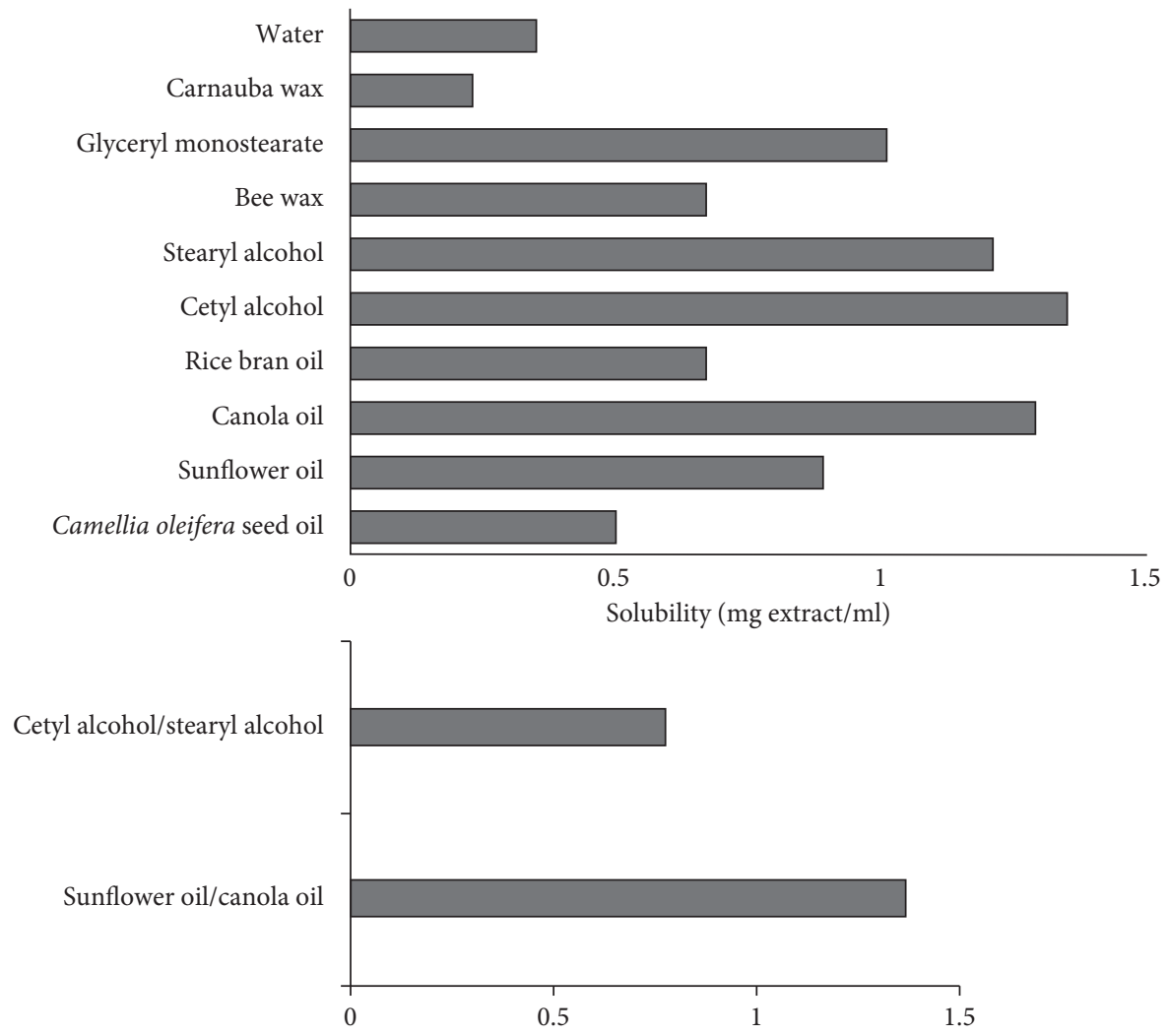

FIGURE 4: Solubility of CP in lipids.

TABle 6: Mean particle size, polydispersity index (PDI), and zeta potential of NLCs with different ultrasonication time and surfactant concentrations.

\begin{tabular}{lccccc}
\hline Placebo-NLCs & Ultrasonication time $(\mathrm{min})$ & Surfactant $(\% \mathrm{w} / \mathrm{w})$ & Particle size $(\mathrm{nm})$ & PDI & Zeta potential $(\mathrm{mV})$ \\
\hline A1 & 5 & 5 & $219.5 \pm 0.5^{\mathrm{a}}$ & $0.3 \pm 0.02^{\mathrm{a}}$ & $-21.7 \pm 0.5^{\mathrm{a}}$ \\
A2 & 15 & 5 & $150.7 \pm 1.5^{\mathrm{b}}$ & $0.3 \pm 0.04^{\mathrm{a}}$ & $-20.7 \pm 0.2^{\mathrm{a}}$ \\
B1 & 5 & 7.5 & $194.9 \pm 2.6^{\mathrm{c}}$ & $0.2 \pm 0.02^{\mathrm{b}}$ & $-30.5 \pm 0.4^{\mathrm{b}}$ \\
B2 & 15 & 7.5 & $152.4 \pm 0.9^{\mathrm{b}}$ & $0.2 \pm 0.01^{\mathrm{b}}$ & $-28.9 \pm 0.8^{\mathrm{b}}$ \\
\hline
\end{tabular}

Different letters within the same column mean significant difference $(p<0.05)$.

(PDI), and zeta potential. An important factor of NLCs preparation is the technique, the final particle size could be affected by the influence of process parameters on sonication including duration and amplitude [31]. All placebo-NLCs had obtained a particle size less than $220 \mathrm{~nm}$, confirming that the particles were produced in the nanosize range. Placebo-NLCs A2 and placebo-NLCs B2 were obtained in a smaller size than placebo-NLCs A1 and placebo-NLCs B1 with a significant difference at $p<0.05$. From the results, it could be explained that the particle size dramatically decreased with higher sonication time. Ultrasonication was used to break down the colloidal to nanoscale by amplitude. Higher amplitude and longer ultrasonication time provided higher energy sound wave to break down the colloidal. In this study, the amplitude of ultrasonication was $40 \%$ that is suitable to produce nanoparticles. Ultrasonication time of 20 min or longer in other placebo-NLCs (data not shown) produced the same particle size as the formulation of $15 \mathrm{~min}$ of ultrasonication time with a wide PDI. Ultrasonication time of about $15 \mathrm{~min}$ regularly provided nanoscale, while 1 to 5 min produced a final particle size of more than $150 \mathrm{~nm}$. Therefore, an appropriate ultrasonication time leads to the production of small particle size because it directly influenced the final particle size of the dispersion. Surfactants in formulation also affected the particle size of placebo-NLCs. Increasing the surfactant concentration from $5 \%$ to $7.5 \%$ in placebo-NLCs B1 resulted in a smaller particle size than placebo-NLCs A1 due to the decreased interfacial tension [32]. The high amount of surfactant decreased the surface tension of lipid drops, breaking down lipid drops to a smaller size. In addition, a suitable amount of surfactant concentration could prevent coalescence of the placebo-NLCs. Cremophor A25 and Span 80 might affect the surface charge that decreased zeta potential value, but it could generate stable formulation by steric effect [33]. The polydispersity index of placebo-NLCs remained in a range of 0.2 to 0.3 .

Placebo-NLCs were evaluated for their stability after 3 months. Placebo-NLCs B2 exhibited good stability with a constant particle size after storage at $4^{\circ} \mathrm{C}$ and room temperature. The particle sizes of the other NLCs were slightly 


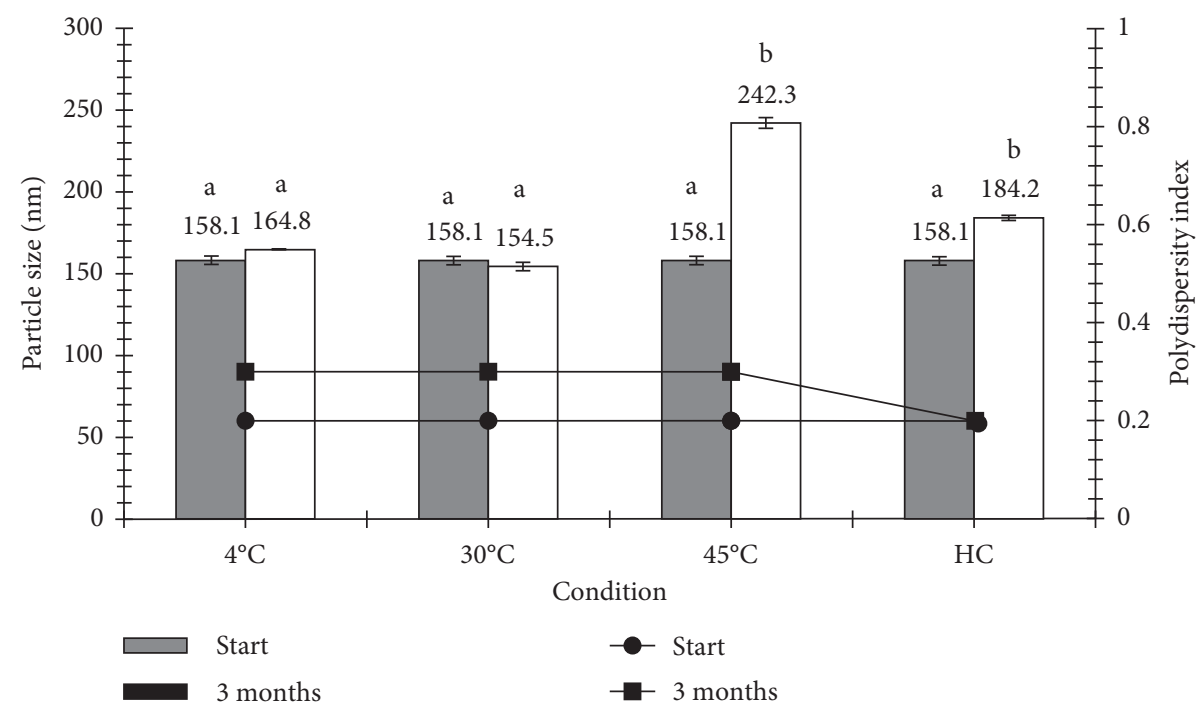

Figure 5: Mean particle size and PDI of CP-loaded NLCs before and after the stability test at different conditions. Different letters mean significant difference $(p<0.05)$.

increasing from the starting time. These results clearly indicated that placebo-NLCs B2 had good properties for loading CP.

3.6.2. Preparation and Stability Study of CP-Loaded NLCs. $\mathrm{CP} 0.5 \% \mathrm{w} / \mathrm{w}$ was loaded in the lipid phase to prepare NLCs and kept at various conditions, heating-cooling $(\mathrm{HC})$ : $4 \pm 0.5^{\circ} \mathrm{C}, 30 \pm 0.5^{\circ} \mathrm{C}$, and $45 \pm 0.5^{\circ} \mathrm{C}$ for 3 months. The physical appearances of CP-loaded NLCs including color and $\mathrm{pH}$ value did not change during storage. The results of the stability study are shown in Figure 5. The particle size, zeta potential, and PDI were $158.1 \pm 2.7 \mathrm{~nm},-29.2 \pm 0.1 \mathrm{mV}$, and $0.2 \pm 0.01$, respectively. Formulations after $\mathrm{HC}$ and at $45^{\circ} \mathrm{C}$ significantly increased the particle size $(p<0.05)$ whereas $4^{\circ} \mathrm{C}$ and room temperature did not affect the particle size of CP-loaded NLCs. Usually, an increase of the particle size and PDI are parameters of instability in the colloidal system [34]. It could be indicated that CP-loaded NLCs slightly changed at high temperature for the long storing period but no coalescence or phase separation occurred.

3.6.4. Antioxidant Activities of CP-Loaded NLCs after Stability Test. Antioxidant activity after storage was evaluated by DPPH and FRAP assays. The results are shown in Figure 6. CP-loaded NLCs exerted nearly $90 \%$ of inhibition by the DPPH assay in all conditions with no significant difference $(p<0.05)$ from the starting values. The results from the FRAP assay were also similar to the starting values especially at $4^{\circ} \mathrm{C}$, but FRAP value slightly decreased under other conditions. The temperature had affected the antioxidant activity of CP-loaded NLCs due to degradation of phenolic compounds after storage. Chlorogenic acid and polyphenols are sensitive to temperature [35]. However, NLCs could help decrease the degradation of phenolic compounds in formulation leading to the preservation of the antioxidant potential.

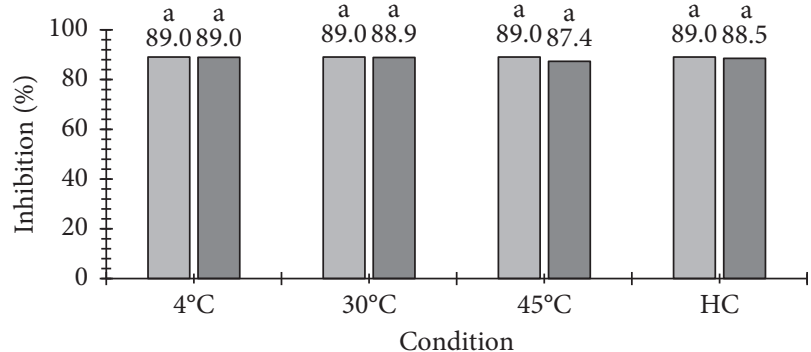

$\square$ Start

3 months

(a)

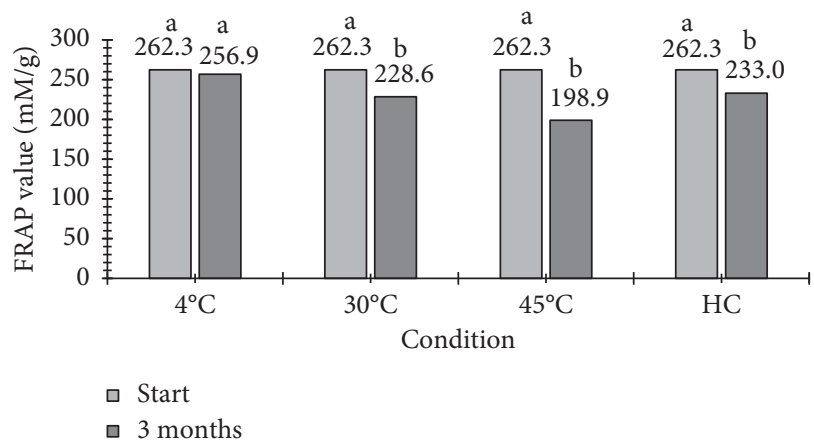

(b)

FIgure 6: Antioxidant activities of CP-loaded NLCs by (a) DPPH and (b) FRAP assays before and after stability test at $4^{\circ} \mathrm{C}, 30^{\circ} \mathrm{C}$, and $45^{\circ} \mathrm{C}$ and heating-cooling (HC) cycles. Different letters within the same condition mean significant difference $(p<0.05)$.

3.7. Entrapment Efficacy and Extract Loading of CP-Loaded NLCs. Entrapment efficacy of chlorogenic acid and caffeine in CP-loaded NLCs was found to be $73.2 \%$ and $62.9 \%$, respectively. Drug loading capacity of chlorogenic acid and caffeine in CP-loaded NLCs was found to be $73.5 \%$ and 


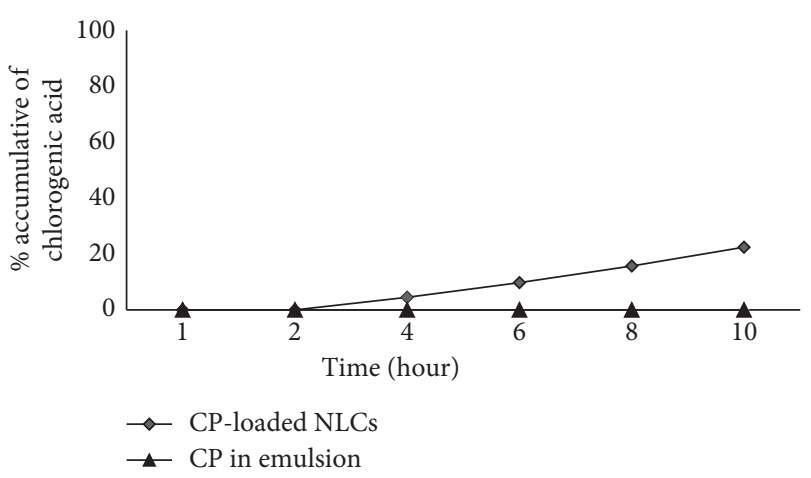

(a)

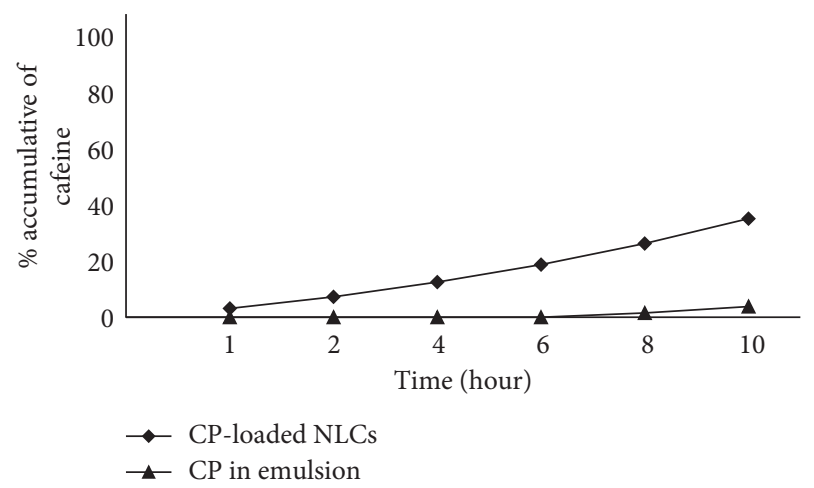

(b)

FIGURe 7: Percentage of accumulative amount of (a) chlorogenic acid and (b) caffeine from CP-loaded NLCs and conventional emulsion after $10 \mathrm{~h}$.

$68.8 \%$, respectively. The mixture of hexane and ethanol could effectively extract the active compound from the lipid matrix for analyzing the amount of the total compound. The extract was entrapped into the lipid matrix due to the structure of NLCs consisting of medium chain triglycerides with free spaces capable of holding a certain amount of the extract. Entrapment efficacy depends on the amount of the lipid, the solubility of the compounds in lipid, and the concentration of the surfactant $[23,36]$. Therefore, increasing the concentration of the lipid matrix and the solubility of the extract in the lipid phase can generate higher encapsulation efficiency.

3.8. Skin Permeation Study by Franz Diffusion Cells. Chlorogenic acid and caffeine in the CP were detected as a marker in the skin permeation study. The percentage of accumulative amounts of chlorogenic acid and caffeine between CP-loaded NLCs and conventional emulsion in the receiver chamber after $10 \mathrm{~h}$ is shown in Figure 7 . Amounts of chlorogenic acid and caffeine remaining in the viable epidermis and dermis (VED) and stratum corneum (SC) from CP-loaded NLCs and conventional emulsion are also shown in Figure 8. NLCs-loaded CP exhibited higher accumulative amount of chlorogenic acid and caffeine than conventional emulsion. Skin samples were extracted after the end of the permeation experiments. The amounts of chlorogenic acid and caffeine from NLCs-loaded CP penetrated into the

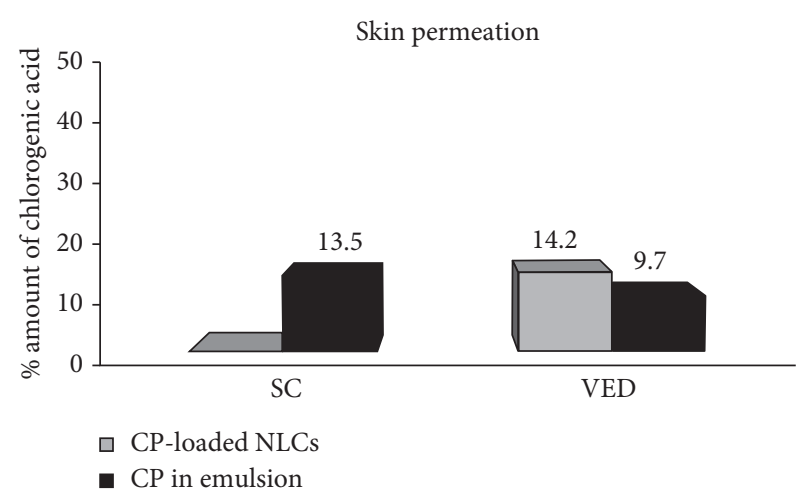

(a)

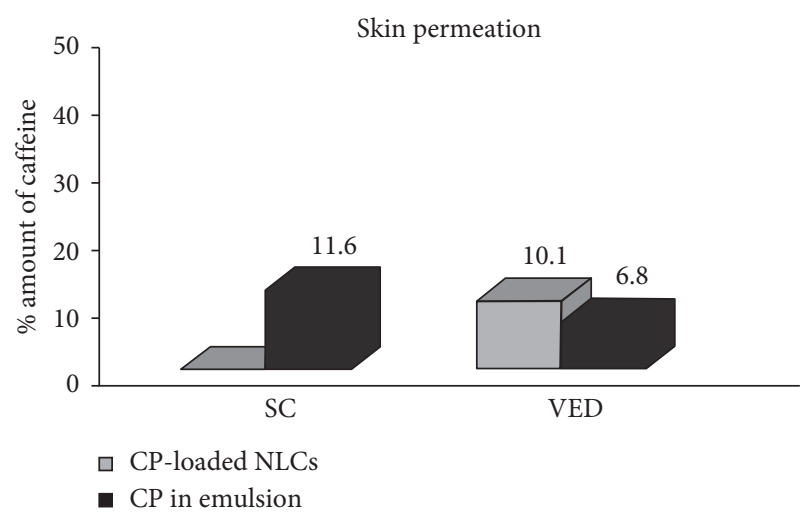

(b)

FIgURE 8: Amount of (a) chlorogenic acid and (b) caffeine in the stratum corneum (SC) and viable epidermis and dermis (VED) after $10 \mathrm{~h}$.

viable epidermis and dermis and receiver solution deeper than conventional emulsion. Furthermore, adhesive tapes were performed as the amounts of chlorogenic acid and caffeine in stratum cornuem (SC). Chlorogenic acid and caffeine from CP-loaded NLCs could not be detected on the stratum corneum whereas conventional emulsion showed a high content of chlorogenic acid and caffeine. The result showed that CP-loaded NLCs could penetrate and deliver the active compound into the skin better than conventional emulsion. In addition, NLCs-loaded CP possessed the property of enhanced skin penetration of the active compound due to small particle size, film former, and occlusive effect $[9,37]$. Conventional emulsion was not able to form film with larger particle size. Those results proved that the particle size and occlusive properties of NLCs formulation achieve a higher penetration of the active compound through the skin.

\section{Conclusion}

Green robusta coffee beans extracts from three different locations in Thailand, including Chumphon, Yala, and Chiang Rai contained caffeine and phenolic compounds including chlorogenic acid and caffeic acid. CP exhibited the highest antioxidant activity shown by DPPH and FRAP assays which correlated to a high amount of chlorogenic acid 
and caffeine in the extract. IL- 6 secretion is decreased by CP indicating an anti-inflammatory potential. Growing coffee at suitable attitude and location was an important factor that related to biological activities of the extract. CP did not irritate the chorioallantoic membrane of hen's eggs, thus can be safely applied to the skin. The CP-loaded NLCs was successfully formulated to improve the stability of the extract and increase skin permeation efficacy. Therefore, the CPloaded NLCs can be further used in cosmeceutical applications.

\section{Data Availability}

The data used to support the findings of this study are available from the corresponding author upon request.

\section{Conflicts of Interest}

The authors declare that there are no conflicts of interest regarding the publication of this paper.

\section{Acknowledgments}

The authors would like to acknowledge the Faculty of Pharmacy and Chiang Mai University for the research grant, financial support, and facilities used in the project. The authors would also like to acknowledge the Department of Pharmaceutical Technology and Biopharmaceutics, University of Vienna, for facilities used in the project. Furthermore, the authors acknowledge short-term grants obtained by the ASEAN-European Academic University Network (ASEA-UNINET).

\section{References}

[1] P. Angkasith, "Coffee production status and potential of organic arabica coffee in Thailand," AU Journal of Technology, vol. 5, pp. 215-219, 2002.

[2] M. Jeszka-Skowron, M. Krawczyk, and A. Zgoła-Grześkowiak, "Determination of antioxidant activity, rutin, quercetin, phenolic acids and trace elements in tea infusions influence of citric acid addition on extraction of metals," Journal of Food Composition and Analysis, vol. 40, pp. 70-77, 2015.

[3] J. A. Vignoli, D. G. Bassoli, and M. T. Benassi, "Antioxidant activity polyphenols caffeine and melanoidins in soluble coffee the influence of processing conditions and raw material," Food Chemistry, vol. 124, no. 3, pp. 863-868, 2011.

[4] A. P. Craig, C. Fields, N. Liang, D. Kitts, and A. Erickson, "Performance review of a fast HPLC-UV method for the quantification of chlorogenic acids in green coffee beans extracts," Talanta, vol. 154, pp. 481-485, 2016.

[5] A. Farah, M. Monteiro, C. M. Donangelo, and S. Lafay, "Chlorogenic acids from green coffee extract are highly bioavailable in humans," Journal of Nutrition, vol. 138, no. 12, pp. 2309-2315, 2008.

[6] R. M. Alonso-Salces, F. Serra, F. Reniero, and K. HÉberger, "Botanical and geographical characterization of green coffee (Coffea arabica and Coffea canephora) chemometric evaluation of phenolic and methylxanthine contents," Journal of Agricultural and Food Chemistry, vol. 57, no. 10, pp. 42244235, 2009.
[7] D. Perrone, A. Farah, C. M. Donangelo, T. de Paulis, and P. R Martin, "Comprehensive analysis of major and minor chlorogenic acids and lactones in economically relevant Brazilian coffee cultivars," Food Chemistry, vol. 106, no. 2, pp. 859-867, 2008.

[8] X. Mu and Z. Zhong, "Preparation and properties of poly vinyl alcohol-stabilized liposomes," International Journal of Pharmaceutics, vol. 318, no. 1-2, pp. 55-61, 2006.

[9] N. Naseri, H. Valizadeh, and P. Zakeri-Milani, "Solid lipid nanoparticles and nanostructured lipid carriers structure, preparation and application," Advanced Pharmaceutical Bulletin, vol. 5, no. 3, pp. 305-312, 2015.

[10] J. Pardeike, A. Hommoss, and R. H. Müller, "Lipid nanoparticles (SLN, NLC) in cosmetic and pharmaceutical dermal products," International Journal of Pharmaceutics, vol. 366, no. 1-2, pp. 170-184, 2009.

[11] K. Iwai, N. Kishimoto, Y. Kakino, K. Mochida, and T. Fujita, "In vitro antioxidative effects and tyrosinase inhibitory activities of seven hydroxycinnamoyl derivatives in green coffee beans," Journal of Agricultural and Food Chemistry, vol. 52, no. 15, pp. 4893-4898, 2004.

[12] T. Osawa and M. A. Namiki, "Novel type of antioxidant isolated from leaf wax of eucalyptus leaves," Agricultural and Biological Chemistry, vol. 45, no. 3, pp. 735-739, 1981.

[13] B. Ou, D. Huang, M. Hampsch-Woodill, J. A. Flanagan, and E. K. Deemer, "Analysis of antioxidant activities of common vegetables employing oxygen radical absorbance capacity (ORAC) and ferric reducing antioxidant power (FRAP) assays a comparative study," Journal of Agricultural and Food Chemistry, vol. 50, no. 11, pp. 3122-3128, 2002.

[14] A. Ayelign and K. Sabally, "Determination of chlorogenic acids (CGA) in coffee beans using HPLC," American Journal of Research Communication, vol. 1, pp. 78-91, 2013.

[15] Y. $\mathrm{Li}$ and $\mathrm{K}$. Bi, "HPLC determination of ferulic acid in rat plasma after oral administration of Rhizoma Chuanxiong and its compound preparation," Biomed Chromatography, vol. 17, pp. 543-546, 2013.

[16] M. Mueller, S. Hobiger, and A. Jungbauer, "Anti-inflammatory activity of extracts from fruits, herbs and spices," Food Chemistry, vol. 122, no. 4, pp. 987-996, 2010.

[17] M. York and W. A. Steiling, "Critical review of the assessment of eye irritation potential using the Draize rabbit eye test," Journal of Applied Toxicology, vol. 18, no. 4, pp. 233-240, 1998.

[18] N. P. Luepke and F. H. Kemper, "The HET-CAM test: an alternative to the draize eye test," Food and Chemical Toxicology, vol. 24, no. 6-7, pp. 495-496, 1986.

[19] W. Chaiyana, C. Punyoyai, S. Somwongin et al., "Inhibition of $5 a$-reductase, IL-6 secretion, and oxidation process of Equisetum debile Roxb. ex vaucher extract as functional food and nutraceuticals ingredients," Nutrients, vol. 9, no. 10, pp. 1105-1122, 2017.

[20] H. Shete and V. Patravale, "Long chain lipid based tamoxifen NLC. Part I preformulation studies formulation development and physicochemical characterization," International Journal of Pharmaceutics, vol. 454, no. 1, pp. 573-583, 2013.

[21] C. L. Ngan, H. R. Masoumi, M. Basri et al., "Development of nanocolloidal system for fullerene by ultrasonic-assisted emulsification techniques based on artificial neural network," Arabian Journal of Chemistry, vol. 14, pp. 167-171, 2016.

[22] S. P. Chaturvedi and V. Kumar, "Production techniques of lipid nanoparticles," Research Journal of Pharmaceutical, Biological and Chemical Sciences, vol. 3, pp. 525-541, 2012.

[23] S. Singh, M. Singh, C. B. Tripathi, M. Arya, and S. A. Saraf, "Development and evaluation of ultra-small nanostructured 
lipid carriers novel topical delivery system for athlete's foot," Drug Delivery and Translational Research, vol. 6, no. 1, pp. 38-47, 2016.

[24] M. Okawa, J. Kinjo, T. Nohara et al., "DPPH (1, 1-diphenyl-2picrylhydrazyl) radical scavenging activity of flavonoids obtained from some medicinal plants," Biological and Pharmaceutical Bulletin, vol. 24, no. 10, pp. 1202-1205, 2001.

[25] I. Gülçin, "Antioxidant activity of caffeic acid (3,4dihydroxycinnamic acid)," Toxicology, vol. 217, no. 2-3, pp. 213-220, 2006.

[26] N. Pellegrini, M. Serafini, S. Salvatore et al., "Total antioxidant capacity of spices, dried fruits nuts pulses cereals and sweets consumed in Italy assessed by three different in vitro assays," Molecular Nutrition and Food Research, vol. 50, no. 11, pp. 1030-1038, 2006.

[27] A. Farah, T. de Paulis, D. P. Moreira, L. C. Trugo, and P. R. Martin, "Chlorogenic acids and lactones in regular and water-decaffeinated arabica coffees," Journal of Agricultural and Food Chemistry, vol. 54, no. 2, pp. 374-381, 2006.

[28] J. H. Hwang, E. J. Koh, Y. J. Lee et al., "Anti-inflammatory effect of caffeine by regulating NF- $\mathrm{kB}$ activation in murine macrophage," FASEB Journal, vol. 30, pp. 256-261, 2016.

[29] J. Leighton, J. Nassauer, and R. Tchao, "The chick embryo in toxicology an alternative to the rabbit eye," Food and Chemical Toxicology, vol. 23, no. 2, pp. 293-298, 1985.

[30] I. D. Rupenthal, C. R. Green, and R. G. Alany, "Comparison of ion-activated in situ gelling systems for ocular drug delivery. Part 1: physicochemical characterisation and in vitro release," International Journal of Pharmaceutics, vol. 411, no. 1-2, pp. 69-77, 2011.

[31] A. J. Van, D. De Wet-Roos, R. D. Sanderson et al., "The role of surfactant in controlling particle size and stability in the miniemulsion polymerization of polymeric nanocapsules," European Polymer Journal, vol. 40, no. 12, pp. 2717-2725, 2004.

[32] T. Delmas, H. Piraux, A. C. Couffin et al., "How to prepare and stabilize very small Nanoemulsions," Langmuir, vol. 27, no. 5, pp. 1683-1692, 2011.

[33] I. F. Uchegbu and S. P. Vyas, "Non-ionic surfactant based vesicles (niosomes) in drug delivery," International Journal of Pharmaceutics, vol. 172, no. 1-2, pp. 33-70, 1998.

[34] P. Witayaudom and U. Klinkesorn, "Effect of surfactant concentration and solidification temperature on the characteristics and stability of nanostructured lipid carrier (NLC) prepared from rambutan (Nephelium lappaceum L.) kernel fat," Journal of Colloid and Interface Science, vol. 505, pp. 1082-1092, 2017.

[35] H. Maier, "Status of research in the field of non-volatile coffee components," in Proceedings of the COLLOQUE Scientifique International sur le Café 15 Montpellier, pp. 6-11, Francia, 1993.

[36] M. S. Gambhire, M. R. Bhalekar, and V. M. Gambhire, "Statistical optimization of dithranol-loaded solid lipid nanoparticles using factorial design," Brazilian Journal of Pharmaceutical Sciences, vol. 47, no. 3, pp. 503-511, 2011.

[37] V. B. Junyaprasert, V. Teeranachaideekul, E. B. Souto, P. Boonme, and R. H. Müller, "Q10-loaded NLC versus nanoemulsions stability rheology and in vitro skin permeation," International Journal of Pharmaceutics, vol. 377, no. 12, pp. 207-214, 2009. 


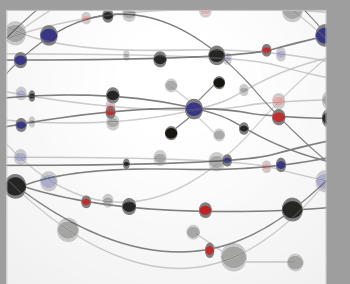

The Scientific World Journal
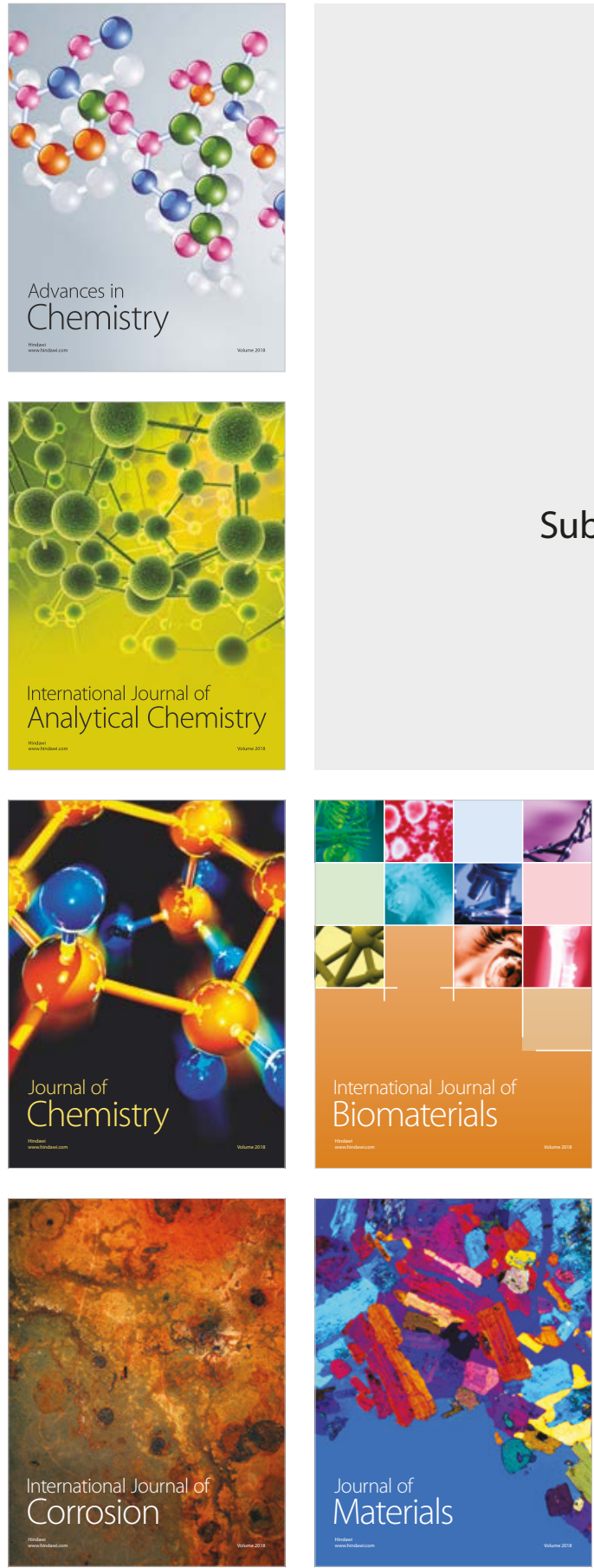

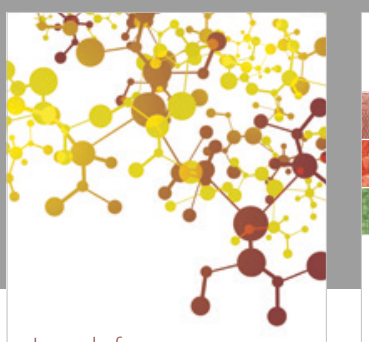

Journal of

Applied Chemistry
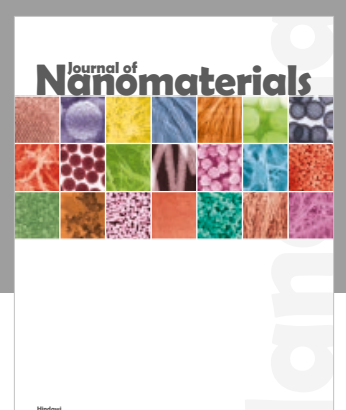

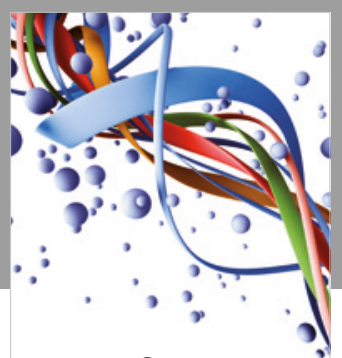

Scientifica

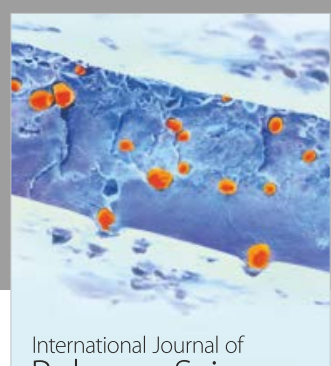

Polymer Science

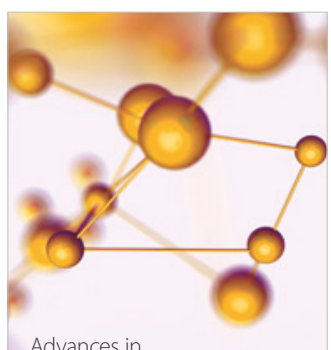

Physical Chemistry
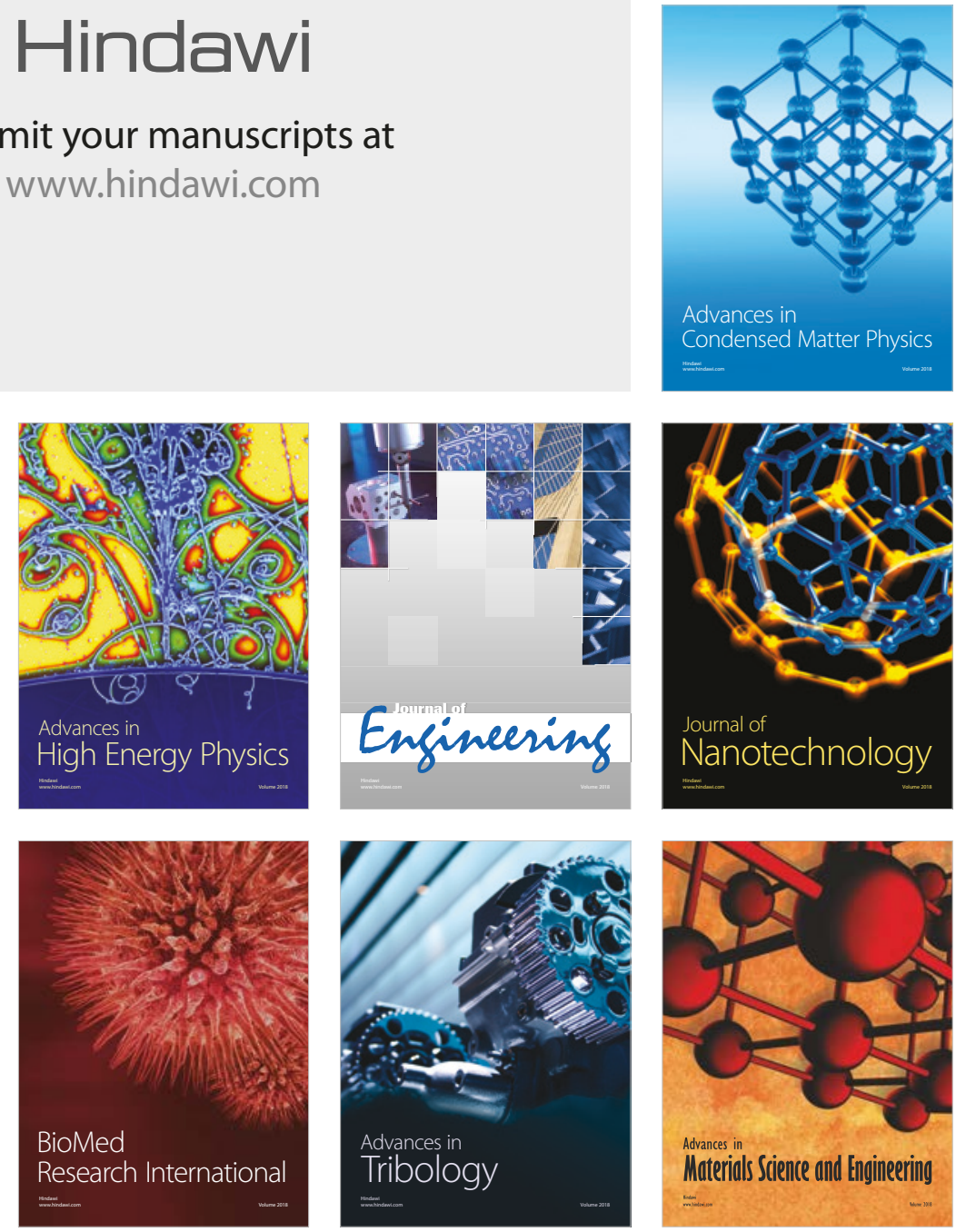